\title{
Recurrent pleural effusion, protein-losing enteropathy, malabsorption, and mosaic warts associated with generalized lymphatic hypoplasia
}

\author{
J. D. ROS S, K. D. G. REID, and V. P. A M B U J A K S H A N \\ Department of Respiratory Diseases and Tuberculosis, City Hospital, Edinburgh \\ J. D. KINLOCH ${ }^{1}$ and W. SIRCUS \\ Gastro-intestinal Unit and Department of Medicine, Western General Hospital, Edinburgh
}

\begin{abstract}
A patient is described who presented with pleural effusions, asymmetrical oedema of the face and limbs, and numerous warts of the hands and feet. He was shown to have vitamin $B_{12}$ malabsorption, steatorrhoea, and a protein-losing enteropathy. Lymphography showed asymmetrical lymphatic hypoplasia. Jejunal biopsy showed intestinal lymphangiectasia. The hypoproteinaemia responded well to a low-fat, high-protein diet. Corticosteroids at first appeared to speed resolution of the pleural effusion but had only a limited effect. The effusion was attributed to infections injuring a lymphatic system already impaired.
\end{abstract}

Abnormal lymphatic drainage giving rise to oedema was first recognised by Letessier in 1865. Subsequently Milroy (1892) described cases with the disease to which his name is eponymously attached.

Pleural effusion associated with lymphoedema and protein-iosing enteropathy was first described by Gordon, Bartter, and Waldmann (1959) who had several patients with chylous ascites and pleural effusions. Subsequently patients with serous pleural effusions and lymphoedema were reported by Jarnum and Petersen (1961), Hurwitz and Pinals (1964), and Emerson (1966).

Features of the patient described in this paper included chronic recurrent pleural effusion, hypoproteinaemia due to protein-losing enteropathy with malabsorption, mosaic warts, asymmetrical peripheral oedema, and generalized lymphatic hypoplasia. The beneficial effect of a low-fat, high-protein diet is described. The pathogenesis of the pleural effusion and the response to corticosteroid therapy are discussed.

\section{CASE HISTORY}

The patient was a man born in 1936. At age 7 he had had suspected mesenteric adenitis and was admitted

1Present address: Chase Farm Hospital, Middlesex to a surgical paediatric unit. No mention was made of oedema or bowel upset at that time. Swelling of the lower legs, right arm, and right side of the face was noted when he was about 12 years old, but no investigation was undertaken until he was 15 when he had a leg fracture due to an accident. He was then found to have a serum albumin level of $2.7 \mathrm{~g} / 100 \mathrm{ml}$ and a maximum total protein level of $5.3 \mathrm{~g} / 100 \mathrm{ml}$. Investigations failed to show the cause, and the hypoproteinaemia was labelled idiopathic. Because of increased oedema further investigations were performed four years later but no additional information was obtained and acetazolamide was given with some improvement in the oedema. One month later he developed a right-sided pneumonia accompanied by a small pleural effusion which cleared with antibiotic therapy. The diuretic was changed to chlorothiazide. About this time warts appeared on the hands and feet.

For the following 10 years his health remained good. He led an active life and became a chartered accountant. His only complaint, apart from mild oedema and warts, was a right hydrocele which was treated surgically.

FIRST ADMISSION TO RESPIRATORY UNIT In December 1965, when he was 29, he was admitted to the City Hospital, Edinburgh, with a two weeks' history of right-sided pleuritic chest pain that had failed to respond to ampicillin. He was slightly febrile. Pitting oedema was present in the lower legs and right arm ; 
there were several warts on both hands and the distal parts of the feet were covered with mosaic warts. The chest radiograph showed a moderate right pleural effusion. Clear straw-coloured fluid was obtained on aspiration with a protein content of $3.2 \mathrm{~g} /$ $100 \mathrm{ml}$. Mesothelial cells, lymphocytes, and many eosinophils were seen on microscopy, but no organisms or LE cells were found. Anti-nuclear factor and LE cells were not present in the blood. The fluid was sterile on ordinary culture and culture for $\mathrm{Myco-}$ bacterium tuberculosis was negative. Blood count and sedimentation rate were normal. The Heaf tuberculin test was positive grade I. Liver and renal function were normal with the exception of the serum proteins which were $5 \mathrm{~g} / 100 \mathrm{ml}$ with a low albumin on electrophoresis. The history suggested an inflammatory cause for the effusion but there was no response to ampicillin and, since tuberculosis remained a possibility, treatment with streptomycin, PAS, and isoniazid was begun. Prednisolone was given for a short period. The effusion diminished rapidly but reaccumulated after prednisolone was stopped. The patient was then free of chest symptoms and felt well. He continued on streptomycin, PAS, and isoniazid as an outpatient. On this treatment the pleural effusion again almost disappeared.

After 10 months of presumed effective and uninterrupted anti-tuberculosis chemotherapy the effusion reaccumulated. Tuberculosis could not, therefore, be accepted as the sole cause of the effusion unless drug resistance was postulated. An alternative aetiology seemed more likely and further investigations were made.

SECOND ADMISSION-26 OCTOBER 1966. The total plasma protein proved to be between 4.3 and $4.9 \mathrm{~g} /$ $100 \mathrm{ml}$, the albumin fraction being between 1.8 and $2.4 \mathrm{~g}$. Clear pleural fluid was aspirated. The cellular content was similar to that observed previously and no organisms were isolated. The fluid contained $2 \cdot 3$ to $3 \mathrm{~g}$ protein $/ 100 \mathrm{ml}, 88$ to $93 \mathrm{mg}$ sugar $/ 100 \mathrm{ml}$, 111 to $119 \mathrm{mg}$ chloride/litre, and $96 \mathrm{mg}$ cholesterol/ $100 \mathrm{ml}$.

Pleural punch biopsy showed non-specific chronic inflammatory appearances, though tuberculosis could not be excluded. An artificial pneumothorax as a preliminary to thoracoscopy showed absence of adhesions. At thoracoscopy the pleura was thick and granular in certain areas. Biopsy from a granular site showed mesothelial cells, lymphocytes, and many eosinophils.

While the pleural effusion was being investigated further studies in collaboration with the Gastrointestinal Unit at the Western General Hospital were undertaken to determine the cause of the hypoalbuminaemia. Urinary tract investigations were normal and also liver function tests except that a bromsulphthalein excretion test showed $7.5 \%$ retention of dye at 45 minutes.

Marked swelling of the mucosal folds of the small intestine with a spiky pattern was demonstrated on barium meal (Fig. 1). Lymphography was carried out using the technique of Kinmonth, Taylor, and Harper (1955) (Fig. 2). No lymphatic trunks were demonstrable on the left side and only one trunk on the right, instead of the usual four. Normal lymph nodes were present in the groins and very few in the region

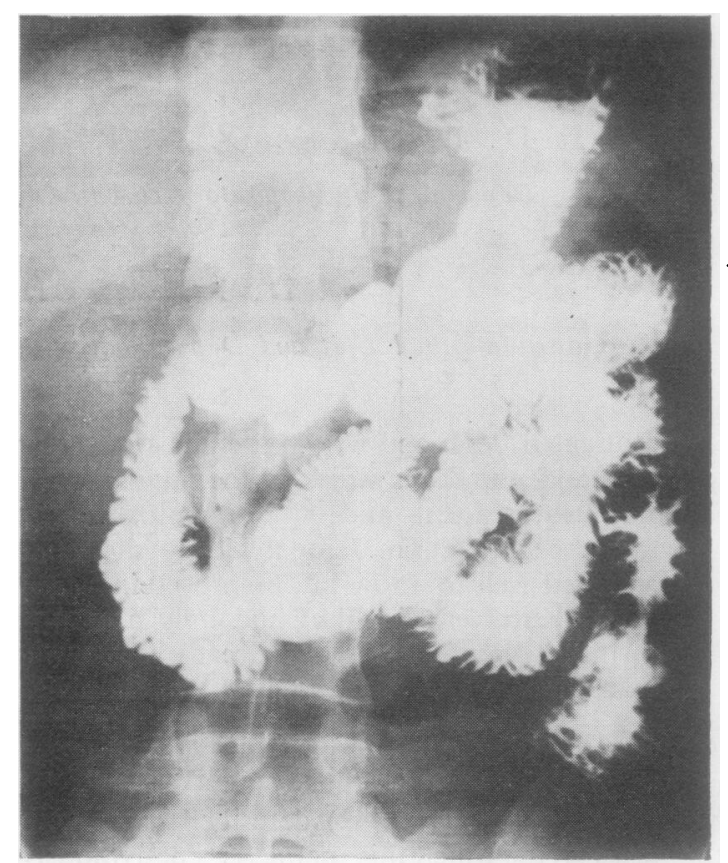

FIG. 1. The appearance of swollen mucosal folds in the jejunum with spiking, as seen in the follow-through of the barium meal.

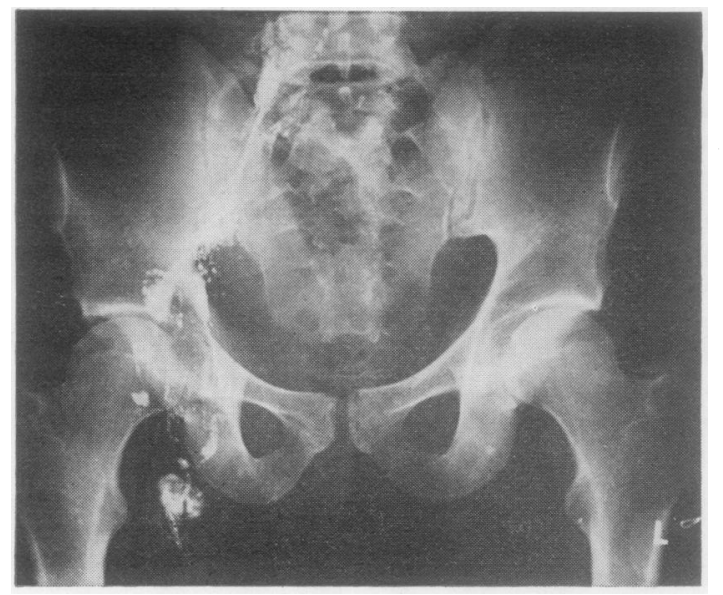

FIG. 2. Lymphogram demonstrates absence of left lymphatics and right lymphatic hypoplasia. 
of the aorta. The appearances were indicative of generalized lymphatic hypoplasia. In view of these findings, it seemed likely that the hypoalbuminaemia was attributable to a protein-losing enteropathy, caused by intestinal lymphangiectasis, despite the lack of any intestinal symptoms.

Faecal fat excretion was raised to $10 \cdot 3 \mathrm{~g} /$ day. Faecal nitrogen was $2 \cdot 2 \mathrm{~g} /$ day (normal $<1 \mathrm{~g}$ ). Serum folic acid was low at $3.5 \mathrm{~m} \mu \mathrm{g} / \mathrm{ml}$ but folic acid absorption was normal. The serum level of vitamin $B_{12}$ was $190 \mu \mathrm{g} / \mathrm{ml}$ and a Schilling test showed only $9 \%$ excretion. The urinary excretion of xylose after 5 hours was $3.6 \mathrm{~g}$ with a $25 \mathrm{-g}$ oral dose. Urinary nitrogen excretion was below the range of normal at $3.6 \mathrm{~g}$ in 24 hours (normal 10-20). 'Maximal' acid output was $18.9 \mathrm{mEq}$ in one hour after stimulation with histamine acid phosphate. ${ }^{125}$ I-labelled polyvinyl pyrrolidone (125IPVP) was given intravenously after blocking the thyroid with iodide. 2.2\% PVP was excreted in the faeces in four days (normal under 1\%) suggesting that the hypoalbuminaemia arose from intestinal loss of proteins.

Under the dissecting microscope, jejunal biopsy showed villi consisting of ridges, mainly convoluted, but no finger villi. White patches were seen on the mucosal surface, from which white fluid, probably chyle, escaped, leaving an empty sac. Histological examination revealed grossly dilated lymphatics in the villi and in the submucosa. The villi containing dilated lymphatics were short and bulbous (Fig. 3). There was no excess fat nor PAS-positive material in the tissue. Impairment of intestinal lymphatic drainage was thus confirmed.

A low-fat, high-protein diet was started and within a few days the serum protein was raised to $6.6 \mathrm{~g} /$ $100 \mathrm{ml}$ of which albumin constituted $3.8 \mathrm{~g} / 100 \mathrm{ml}$. Peripheral oedema almost disappeared and the pleural effusion diminished considerably but not entirely (Figs 4 and 5). A chromosome study of a buccal smear showed no abnormality and there was no family history of a similar disease.

SUBSEQUENT PROGRESS After discharge from hospital small doses of an oral diuretic were continued, as was anti-tuberculosis treatment to eliminate any possible tuberculous disease. We stopped PAS (which may be an intestinal irritant), and ethambutol was given as the companion drug to isoniazid since the patient was unwilling to have more streptomycin injections. No side effects were noted from the ethambutolisoniazid regime which was continued until he had

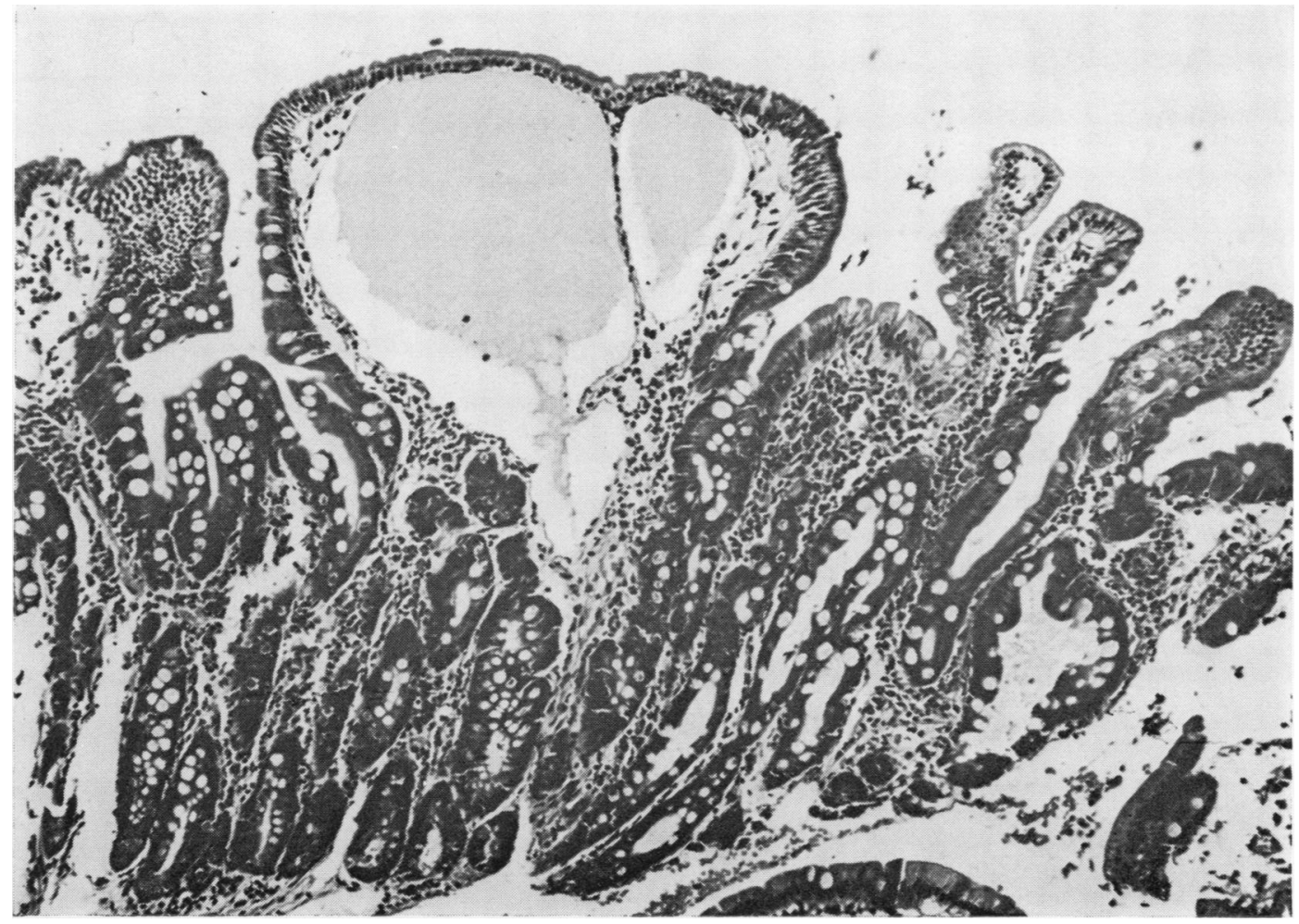

FIG. 3. Gross dilatation and sacculation of intravillous lymphatics in a section of jejunal mucosa. 


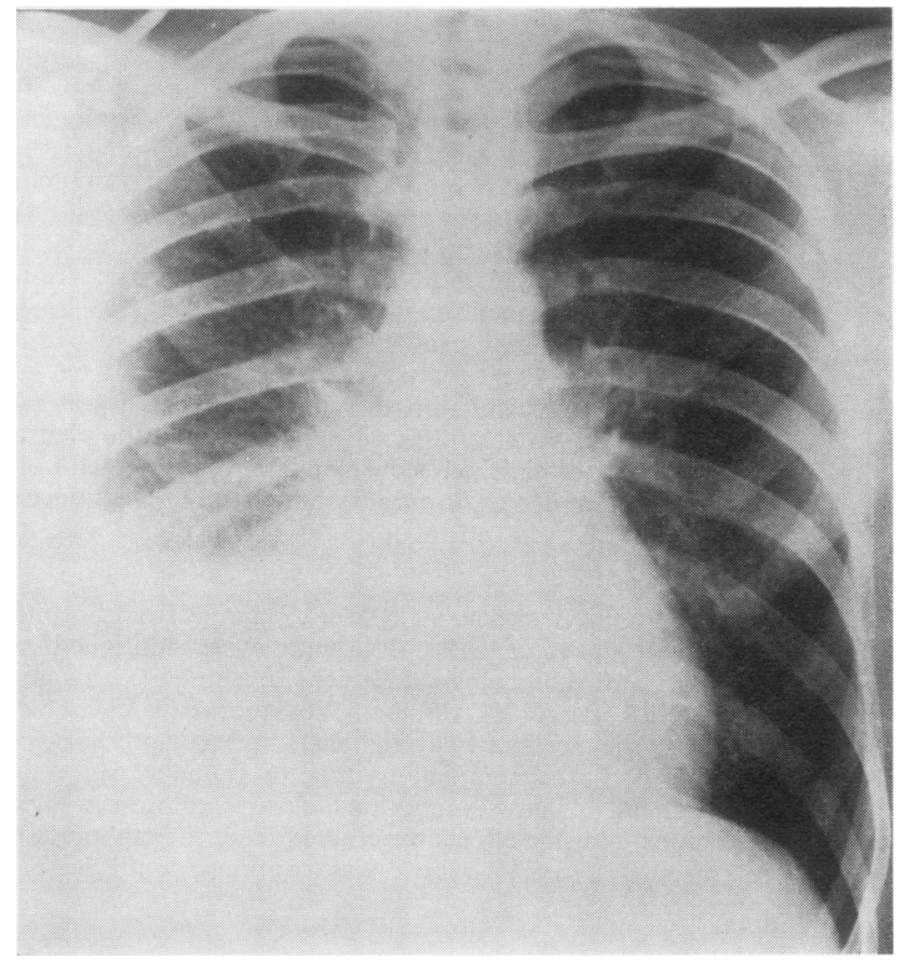

FIG. 4. Right pleural effusion on referrat (15 December, 1965).

FIG. 5. Small pleural effusion remains (26 February, 1967). Subsequent appearances unaltered. 
completed 19 months of anti-tuberculosis chemotherapy. Although the pleural effusion had diminished it persisted despite serum protein levels remaining normal as he continued on a low-fat diet. In July 1967, while he was still on anti-tuberculosis therapy, it was decided to observe again the response to prednisolone. This resulted in further reduction of the effusion. While on the low-fat diet and a small maintenance dose of prednisolone ${ }^{125}$ IPVP faecal excretion studies were repeated and the result was just within normal limits at $0.97 \%$ in four days. $191 \mathrm{I}$ albumin studies performed simultaneously using a double isotope technique did not reveal any enteric loss.

The patient remains in good health his only treatment now being a low-fat diet and a diuretic. There is no pitting peripheral oedema but there is still a possible minimal pleural effusion (June 1970). The last pleural aspiration was on 8 May 1968 when $50 \mathrm{ml}$ of clear yellow fluid was obtained. The total protein level of the fluid was $3.3 \mathrm{~g} / 100 \mathrm{ml}$, of which $2.3 \mathrm{~g}$ was albumin, corresponding serum levels being $6.4 \mathrm{~g} /$ $100 \mathrm{ml}$ and $3.9 \mathrm{~g} / 100 \mathrm{ml}$. The cholesterol level in the fluid was $8.0 \mathrm{mg} / 100 \mathrm{ml}$, total lipids being $330 \mathrm{mg} /$ $100 \mathrm{ml}$. The blood cholesterol level was $168 \mathrm{mg} /$ $100 \mathrm{ml}$. These findings indicated that the remaining pleural fluid was a clear exudate, cholesterol and total lipids being normal in relation to the protein content. The different constitution of the pleural fluid as compared with earlier specimens is of interest. While he was still hypoalbuminaemic before dietary measures had been undertaken the pleural fiuid protein level was as high as $3.0 \mathrm{~g} / 100 \mathrm{ml}$, while the blood level of total proteins was only $4.3 \mathrm{~g} / 100 \mathrm{ml}$, of which $1.8 \mathrm{~g}$ was albumin. At that time also the cholesterol content of the pleural fluid was $96 \mathrm{mg} /$ $100 \mathrm{ml}$, in contrast to $8.0 \mathrm{mg} / 100 \mathrm{ml}$ in a later specimen.

\section{DISCUSSION}

It was considered that the peripheral oedema might be attributable entirely to hypoalbuminaemia but the plasma albumin levels were not sufficiently low to be the sole explanation. In view of the relatively high protein content in the pleural fluid hypoalbuminaemia could not be accepted as the cause of the effusion. The distribution of the oedema was also asymmetrical. After trial therapy with anti-tuberculosis drugs the underlying mechanism was revealed by lymphography and confirmed by jejunal biopsy. The ${ }^{125}$ IPVP test indicated the probability that intestinal protein loss was primarily responsible for the hypoalbuminaemia, but impaired absorption of fat and vitamin $\mathbf{B}_{12}$ was also demonstrated. In keeping with the diagnosis was the prompt response to a low-fat high-protein diet which relieves the intestinal lymphatics of the chylomicron load imposed by long-chain triglycerides in the diet, as has been found by others (Holman, Nickel, and
Sleisenger, 1959). Relief of the lymphatic overdistension is believed to prevent the fat and protein loss caused by lymphatic rupture and resulting loss of chyle into the bowel lumen.

In our patient, the generalised lymphatic disorder involved both legs, the right arm, the right side of the face, and the mesentery; it is believed that abnormal lymphatic drainage contributed also to the right pleural effusion. The drainage of the lymphatics from the lower limbs, intestines, left chest, and arm is commonly into the thoracic duct. On the right side lymphatics draining the arm, neck, chest, and liver usually have separate entrances into the subclavian, internal jugular, or innominate vein. No single central lesion of the lymphatics can account for the distribution of the lymphatic obstruction in this case.

Lymphatic obstruction in cases with an onset in infancy and a family history of the disorder suggest a congenital defect. However, in this instance, the onset was at 12 years, there was no family history, and the disorder may have been acquired. The virus causing the warts might have been postulated as a contributing factor, had it not been that warts first appeared seven years after the onset of oedema. The persistence and spread of the warts might have been a consequence of the long-standing oedema, yet the left hand, which was more affected by warts than the right, was not oedematous.

The recurrence of the pleural effusion after 10 months of anti-tuberculosis therapy appeared to exclude tuberculosis as the sole cause. The return to normal of the serum proteins failed to bring about resolution of the effusion. Coincident with the administration of the first course of prednisolone there was a big reduction in the size of the effusion, though without any effect on the peripheral oedema. A subsequent course of corticosteroids resulted in a further but limited reduction in the effusion without reaccumulation after they were stopped. A beneficial effect from corticosteroid therapy has not been described in this condition. It is possible that the lesions in the alimentary and respiratory systems may have been caused by recurrent episodes of inflammation in the lymphatics and might be responsive to corticosteroids. Such episodes could have been due to infection, allergy, or an autoimmune reaction giving rise to lymphangitis, thus impairing further the already reduced lymphatic drainage. We think that if corticosteroids are given sufficiently early to patients developing lymphatic obstruction syndromes, irreversible obliteration of the lymphatics might be prevented. 
We support the view of Emerson (1966) that lymphatic drainage should be investigated in patients with undiagnosed chronic pleural effusions. In his series hypoproteinaemia, malabsorption, and warts were not described, but yellow nails described by him were not a feature in our case. The high-protein level in the pleural fluid was in keeping with impaired lymphatic drainage. In pleural effusions due to hypoproteinaemia the protein content of the fluid is low. Eosinophils as well as lymphocytes and mesothelial cells were conspicuous in the fluid and pleural biopsy. Das and Sen (1968) have reported a series of patients with filariasis and chylous arthritis with similar histopathology in synovial biopsies and suggested that lymphatic fistulation into the synovial sac might set up an allergic response to proteincontaining chylomicrons. In our case it appears that inflammatory reactions in the pleura interfering with already impaired drainage might have provoked such a reaction, the response to prednisolone being attributable to its anti-inflammatory or anti-allergic actions.

We express our thanks to Mr. R. J. M. McCormack for the thoracoscopy, to Dr. G. A. G. Peterkin for the dermatological assessment, to Dr. D. G. Sinclaig for the lymphogram, and to Dr. E. B. French fo, helpful suggestions.

\section{REFERENCES}

Das, G. C., and Sen, S. B. (1968). Chylous arthritis. Bri $\vec{\square}$ med. J., 2, 27.

Emerson, P. A. (1966). Yellow nails, lymphoedema and pleural effusions. Thorax, 21, 247.

Gordon, R. S., Jr., Bartter, F. C., and Waldmann, T. (1959展 Idiopathic hypoalbuminemias: clinical staff conference at the National Institutes of Health. Ann. intern. Medọ $51,553$.

Holman, H., Nickel, W. F., and Sleisenger, M. H. (1959 Hypoproteinemia antedating intestinal lesions, an $\otimes^{\circ}$ possibly due to excessive serum protein loss into the intestine. Amer. J. Med., 27, 963.

Hurwitz, P. A., and Pinals, D. J. (1964). Pleural effusion in chronic hereditary lymphedema. (Nonne, Milrop Meige's disease). Report of two cases. Radiolog, 82, 246.

Jarnum, S., and Petersen, V. P. (1961). Protein-losing enteropathy. Lancet, 1, 417.

Kinmonth, J. B., Taylor, G. W., and Harper, R. K. (1955) Lymphangiography: a technique for its clinical use in the lower limb. Brit. med. J., 1, 940.

Letessier, E. E. (1865). Thesis (Strasbourg).

Milroy, W. F. (1892). An undescribed variety of hereditaro oedema. N. Y. med. J., 56, 505. 